\title{
Taking care of sick patients
}

$\mathrm{O}$ ver the years, I've noticed something odd. Some physicians are reluctant to care for sick patients, but more surprisingly, they are not afraid to say it.

In medical school, my classmates studied the specialties: "I think I want to do dermatology. I like seeing a range of patients - not just the sick ones." Some of our professors were in on it: "The best part about pediatrics is that most of your patients are well!" And, even in my current field - medical oncology - I find surprising assertions: "I think I'm going to do breast or lymphoma. Something where most patients do well."

What is going on here? Did I miss a memo? Is caring for the ill a burden? I was under the impression that taking care of the sick was the noblest part of being a physician. A series of famous physicians had misled me. First Hippocrates: "Whatever houses I may visit, I will come for the benefit of the sick." Of course, now it was clear. He forgot to clarify, "well, not that sick." Then Maimonides: "Thou has appointed me to watch over the life and death of Thy creatures." But, only from a distance, of course. And, the 19th century physician, Martin Fischer: "Diagnosis is not the end, but the beginning of practice." Unless that diagnosis is dire, in which case, perhaps it is best the beginning of someone else's practice.

I know that caring for those closest to death can be wrenching. Researchers have studied the way in which oncologists cope with the loss of a patient often not well, ${ }^{1}$ but no one has put it more eloquently than David Hilfiker: "All of us who attempt to heal the wounds of others will ourselves be wounded" ${ }^{2}$ " And yet, risking one's rosy world view is a double-edged sword. Just as it can hurt, it can afford emotional clarity. Holding someone's hand, listening or even simply wishing them well, can lift the dead weight of anxiety beyond any medication. A few months

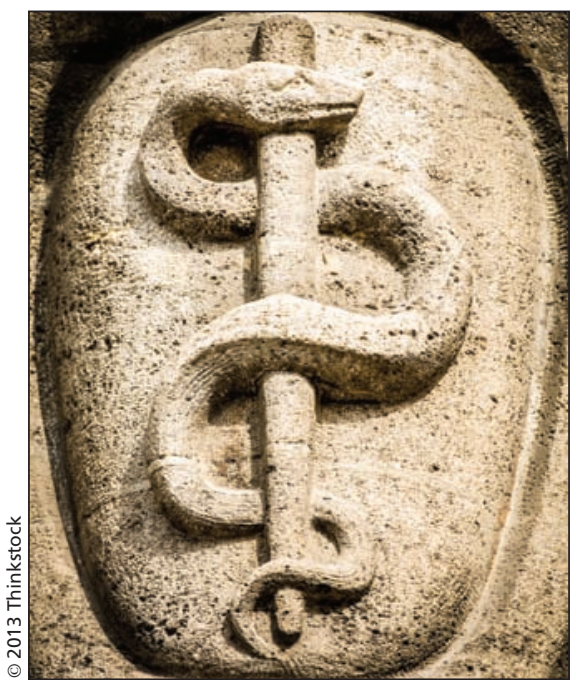

ago, a tearful patient with pancreatic cancer confided in me that she was being treated only for the sake of her children. If she were alone in the world, she would just give up. What did I say? Nothing. I held her hand, and we sat in silence.

Medical oncology remains in the top half of physician specialties when ranked by job satisfaction. ${ }^{3}$ Should that provide us with any more reason to pursue it? Or is the fact it is not number one more reason to avoid it? If taking care of the sick is lumped alongside the other undesirable bits of being a physician - paperwork, claim filing and malpractice - satisfaction may be an imperfect guiding metric.

Does something change on the path to becoming a physician that it becomes reasonable not only to avoid, but to admit to avoiding the sickest among us? Applicants to medical school report altruism as one of their deepest guiding principles,${ }^{4}$ and yet, when junior physicians decide on specialties, altruism plummets down their hierarchy of considerations. It is as if students are soldiers, brimming with bravado, volunteering for the front lines, but when the first bullet whizzes past, they apply for a post in the rear. When I was a student, one classmate created a single equation to rank the specialties - using median hours worked, median income and job satisfaction. The resulting calculus cast improbable fortunes: try to pursue dermatology, but as a back-up, consider pediatric emergency medicine.

I suspect the aversion to illness among some physicians is part of the reason why we, as a profession, have drifted to over diagnosing the well. Clinics need to be full, but certainly not full of sick patients. A few patients with lead-time bias permits busy doctors to regain the lead on the day's schedule. But, illness is not kind. It often ends in cascades of malady. Being a physician is not always tidy.

There are still doctors in the world today who risk their physical wellbeing, but many trainees seem reluctant to risk their social calendar. When fear of AIDS ran rampant, some physicians asked if every doctor had a duty to care for such patients or merely the profession as a whole. ${ }^{5}$ Many answered a resounding yes, every doctor does, with Emanuel summarizing, "the objective of the medical profession is devotion to a moral ideal - in particular, healing the sick and rendering the ill healthy and well."."

We have allowed the dialogue around choosing a specialty to centre on practicality - lifestyle, hours and compensation - and not purpose. Given my talents, what is the best purpose for my life's work? As Socrates remarked about such questions, "We are discussing no small matter, but how we ought to live."

Vinay Prasad MD

Medical Oncology Branch, Fellow

National Cancer Institute

National Institute of Health

Bethesda, Maryland

Disclaimer: The views and opinions of the author do not necessarily reflect those of the National Cancer Institute or the National Institutes of Health.

CMAJ 2013. DOI:10.1503/cmaj.130047 